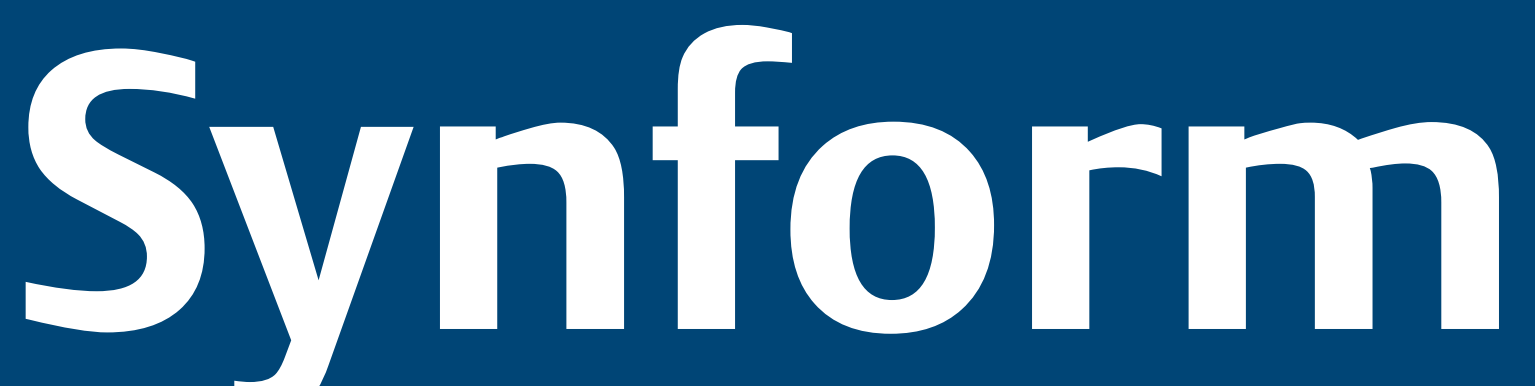

People, Trends and Views in Chemical Synthesis 2017/02

\title{
Deoxyfluorination of Alcohols with 3,3-Difluoro-1,2-diarylcyclopropenes
}

Highlighted article by L. Li, C. Ni, F. Wang, J. Hu

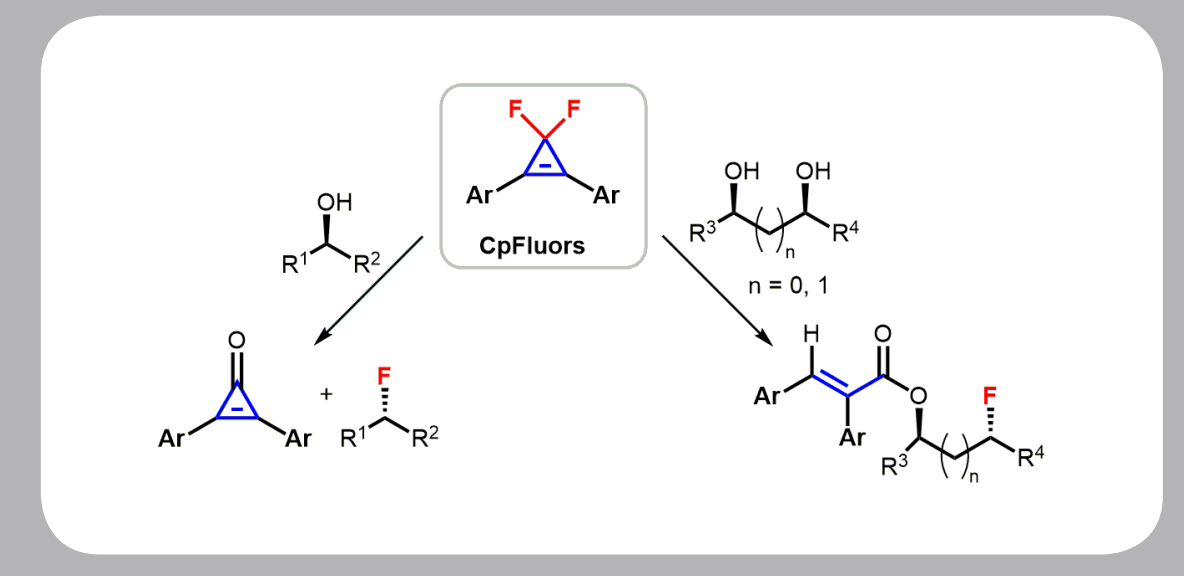

\section{Contact}

Your opinion about Synform is welcome, please correspond if you like: marketing@thieme-chemistry.com 


\section{Dear Readers,}

There are already rumors among UK-based academic chemists that some departments - in preparation to the next Research Excellence Framework (REF-2021), the system for assessing the quality of research in UK higher education institutions - are informing staff that there is little or no interest in considering articles published in journals with Impact Factors lower than 9 or 10. Can you believe it? Well, I do. Even though luckily - I haven't received this recommendation myself (yet?). Because this is exactly the atmosphere we are breathing in our universities, and not just in the UK, where overzealous administrators and bureaucrats with backgrounds in statistics and corporate management have predominantly taken over our departments, schools and colleges. So, in the absence of any understanding of research and its delicate mechanisms, these alien university managements are increasingly judging our performance using metrics like impact factors and citation numbers which - insulated from their context - are just like lottery numbers, devoid of any actual meaning, let alone being scores for measuring the performance of researchers. I appreciate that this is a very complex issue, which cannot be treated with the necessary depth in a brief editorial like this one, but I would encourage you to send me your comments and experience by e-mail or through the SYNFORM website. Let's move on from this impact factors lunacy for the moment, and let's have a look at the content of this exciting February issue of SYNFORM. We start with Uchiyama's (Japan) Ni-catalyzed Stille coupling and continue with Wang's (P. R. of China) computer-assisted synthesis of $3(2 H)$-furanones. The third contribution concerns a novel HPLC-purification-free synthesis of proteins developed by Seitz (Germany). Finally, Hu's (P. R. of China) novel deoxyfluorination reagents com-

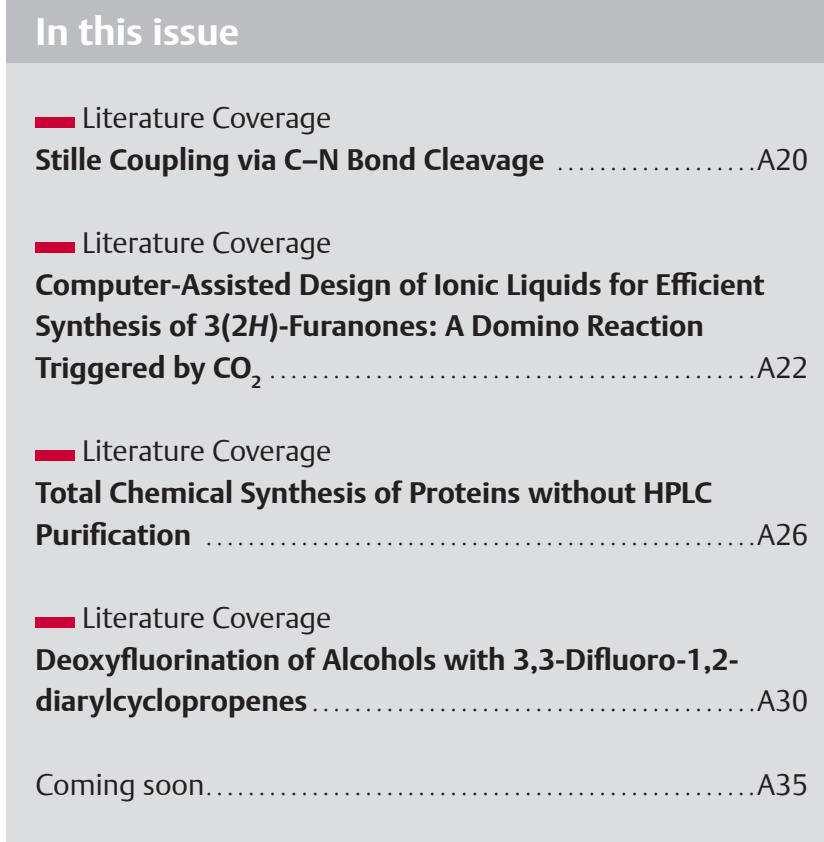

\section{Contact \\ If you have any questions or wish to send feedback, please write to Matteo Zanda at: synform@outlook.com}

plete the issue. No impact factors, or other odd numbers, here. Just great chemistry.

Enjoy your reading!

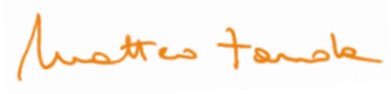




\section{Stille Coupling via C-N Bond Cleavage}

Nat. Commun. 2016, 7, 12937

Biaryls are privileged structures that continue to attract enormous interest for their many applications as drugs and materials. The Stille cross-coupling reaction is one of the most often used methods for assembling biaryls via $\mathrm{C}-\mathrm{C}$ bond formation between the two aromatic rings. The classical version of this reaction uses aryl stannanes and aryl halides as substrates, while the catalyst is a Pd complex.

Recently, the group of Professor Masanobu Uchiyama from The University of Tokyo (Japan) reported the first Ni-catalyzed Stille coupling of quaternary ammonium salts via $\mathrm{C}-\mathrm{N}$ bond cleavage. Professor Uchiyama said: "In a process catalyzed by commercially available $\mathrm{Ni}(\operatorname{cod})_{2}$ and an imidazole ligand, aryl- and alkyltrimethylammonium salts $\left[\mathrm{Ar} / \mathrm{R}-\mathrm{NMe}_{3}\right]^{+}$react smoothly with arylstannanes in a 1:1 molar ratio to give the corresponding cross-coupling products in high yields with broad functional group compatibility, providing a highly efficient and practical way for constructing diverse $\mathrm{C}-\mathrm{C}$ bonds from quaternary ammonium salts."

With regard to the utilization of amines as electrophiles and their pre-activation, Professor Uchiyama pointed out that amine groups occur widely in natural products, and are also found in many pharmaceuticals, dyes, and functional molecules: "A large variety of amines are commercially available, mostly at reasonable cost. However, transformation of the $\mathrm{NR}_{2}$ group is generally difficult, due to the chemical inertness of the $\mathrm{C}-\mathrm{N}$ bond. Most ammonium salts can be obtained in high or even quantitative yield just by treating the original amines with electrophiles such as RX (halides), MeOTf, etc., under mild conditions. In many cases, simple filtration can provide sufficient purity of these compounds for subsequent uses. Furthermore, ammonium salts can be easily stored in air at room temperature without any decomposition. Therefore, the ammonium salt is an ideal pre-activation form for an amine."

Nowadays, in place of Pd, many other transition metals have been used for various types of cross-coupling reactions, with $\mathrm{Ni}$ being widely applied. However, Ni-catalyzed Stille couplings have been reported only rarely, with the latest case reaching back to 1995 (V. Percec, J.-Y. Bae, D. H. Hill J. Org. Chem. 1995, 60, 6895). The current work establishes a new and efficient protocol for using $\mathrm{Ni}$ compounds as the catalyst in Stille coupling reactions. Professor Uchiyama explained: "By employing a combination of experimental and computational methods, the present work also provides a comprehensive reaction profile, which explains the mechanistic details well, especially those key issues involving: a) how $\mathrm{C}-\mathrm{N}$ bond cleavage takes place with $\mathrm{Ni}$, and $\mathrm{b}$ ) what controls the $\mathrm{Ni} / \mathrm{Sn}$

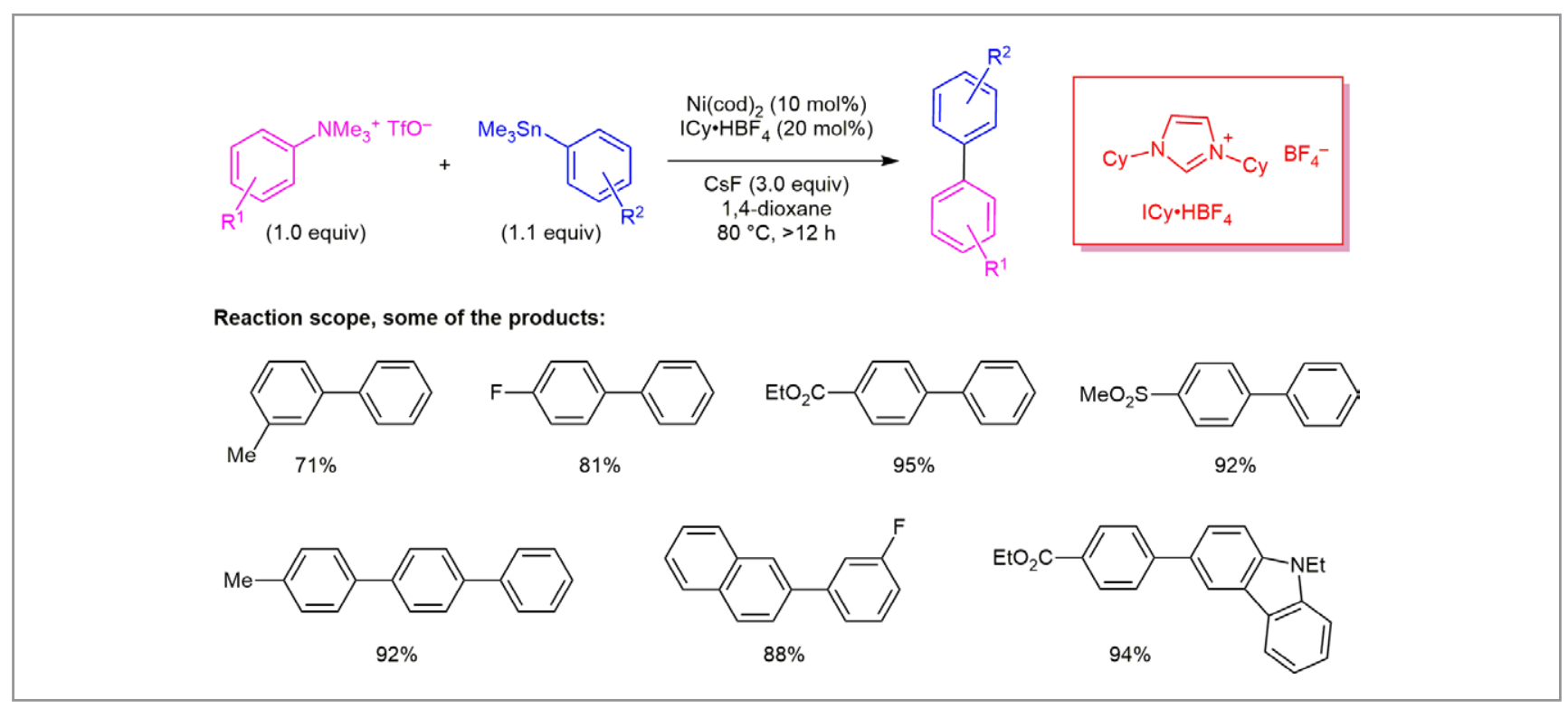

Scheme 1 
transmetalation." He concluded: "These results should be helpful for understanding other related organometallic reactions as well as designing new cross-coupling protocols."



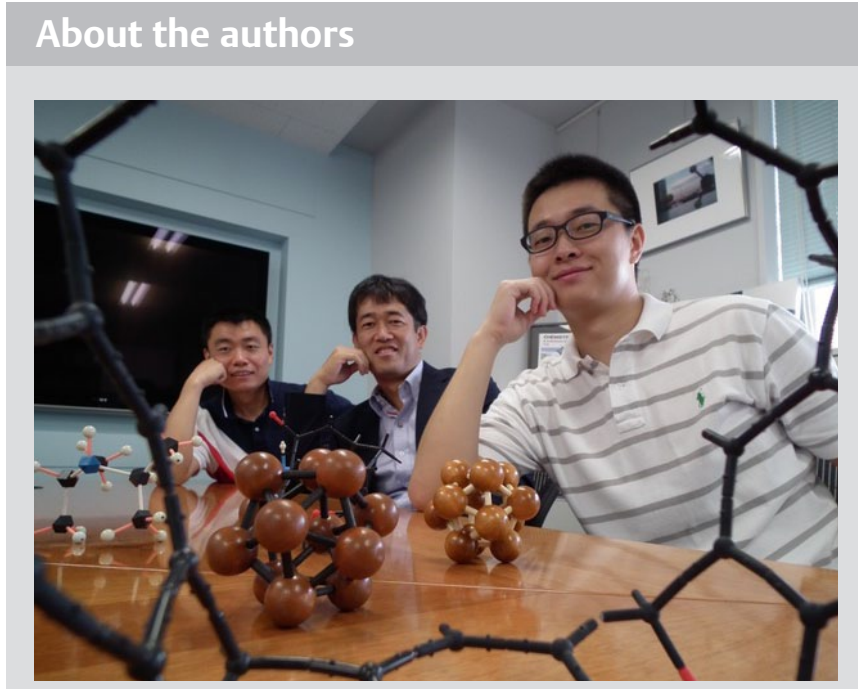

From left: Dr. C. Wang, Prof. M. Uchiyama, Dr. D.-Y. Wang

Dong-Yu Wang was born in Liaoning Province (P. R. of China) in 1986. He received his BS degree from Shenyang Pharmaceutical University (P. R. of China) in 2010 and then became a graduate student under the supervision of Professor Youjun Xu in the same university. During his Master's course, he also studied at the Shanghai Institute of Materia Medica, Chinese Academy of Sciences (P. R. of China), as an exchange student in Professor Ao Zhang's lab. In October 2013, he joined Professor Masanobu Uchiyama's group at the Graduate School of Pharmaceutical Sciences, The University of Tokyo (Japan), and obtained his PhD in 2016. He is now doing postdoctoral research with Professor Ao Zhang at the Shanghai Institute of Materia Medica, Chinese Academy of Sciences.
Chao Wang obtained his BS degree in 2002 from Peking University (P. R. of China). He carried out doctoral research under the supervision of Professor Zhenfeng $\mathrm{Xi}$ in the same university and obtained his PhD in 2007. During 2007-2008, he carried out postdoctoral research at Purdue University (USA) with Professor Ei-ichi Negishi. In 2009, he joined Professor Uchiyama's lab as a JSPS Postdoctoral Fellow and is now an Assistant Professor of the same lab at the Graduate School of Pharmaceutical Sciences, The University of Tokyo (Japan). His research involves synthetic organic chemistry, organometallic chemistry, and theoretical and computational chemistry.

Masanobu Uchiyama obtained his MS degree (1995) and PhD (1998) from The University of Tokyo (Japan). He worked as an Assistant Professor at Tohoku University (1995-2001) and The University of Tokyo (2001-2003), and was promoted to Lecturer (2003-2006). From 2001-2004, he served concurrently as PI of a PRESTO project of JST. He became Associate Chief Scientist (PI) at RIKEN (Japan) in April 2006. Since April 2010, he has been a Full Professor at the Graduate School of Pharmaceutical Sciences, The University of Tokyo, and has also held the post of Research Team Leader (PI) and Chief Scientist (PI, since 2013) at RIKEN. His research interests cover a variety of areas including organic synthesis, organometallics, theoretical chemistry, materials, medicines and spectroscopy. He has received many prizes and awards including the Banyu Young Chemist Award (1999), The Pharmaceutical Society of Japan Award for Young Scientists (2001), the Incentive Award in Synthetic Organic Chemistry, Japan (2007), The Commendation for Science and Technology by the Minister of Education (The Young Scientists' Prize, 2009), and the SSOCJ Nissan Chemical Industries Award for Novel Reaction \& Method (2014). 


\title{
Computer-Assisted Design of Ionic Liquids for Efficient Synthesis of 3(2H)-Furanones: A Domino Reaction Triggered by $\mathrm{CO}_{2}$
}

\author{
J. Am. Chem. Soc. 2016, 138, 14198-14201
}

$\mathrm{CO}_{2}$ capture and utilization ( $\mathrm{CCU}$ ) has attracted much attention during this decade in the context of green economy. Ionic liquids (ILs) exhibit particularly attractive properties for CCU, due to their tunable structures that can be harnessed for absorption and activation of $\mathrm{CO}_{2}$. Recently, the group of Professor Congmin Wang at Zhejiang University (P. R. of China) discovered that the basicity of ILs is the key to influencing the gas absorption capacity, such as in the case of $\mathrm{CO}_{2}$ and $\mathrm{SO}_{2} \cdot{ }^{1}$ In addition, a moderate basicity of IL is also crucial to ensuring its high catalytic activity in the synthesis of alkylidene carbonates from propargylic alcohols and atmospheric-pressure $\mathrm{CO}_{2}{ }^{2}$ Previously, the choice of base catalysts was often based on experience and experiment trial and error. Professor Wang explained: "We wanted to develop an innovative strategy to easily predict the best range of basicity by DFT calculations. If that worked, it would save more time on catalyst screening."



$1 a$<smiles>CC1(C)OC(Cc2ccccc2)=CC1=O</smiles>

$2 a$

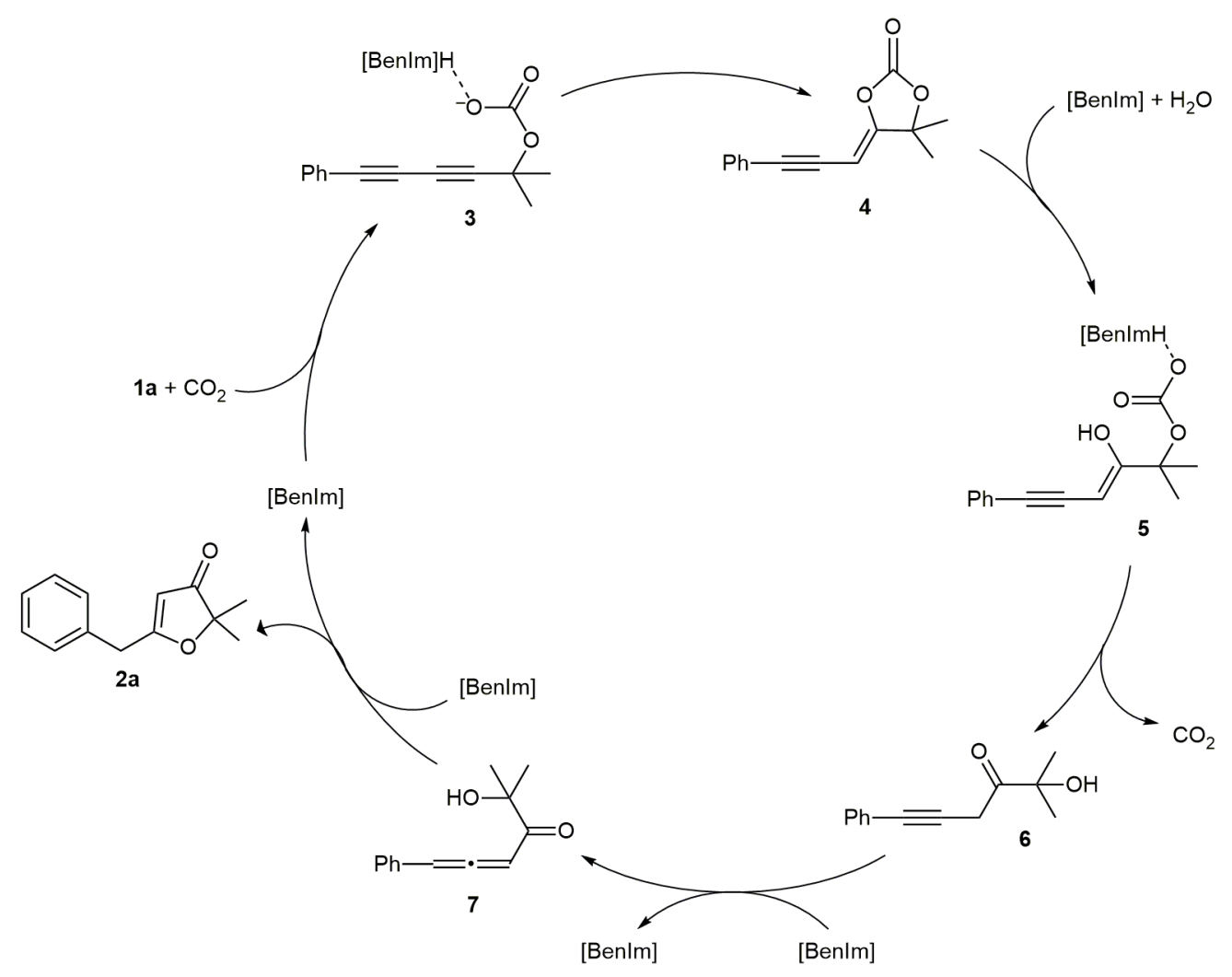

Scheme 1 Hydration of diyne alcohol 
Professor Wang continued: "The $\mathrm{CO}_{2}$-triggered domino reaction to achieve the synthesis of $3(2 \mathrm{H})$-furanones was selected as the model reaction (Scheme 1). There are two reasons for our choice of this reaction: 1) 3(2H)-furanones are important structures in many natural products; therefore, an environmentally benign method of synthesizing them was expected to be of profound significance; 2 ) this reaction can occur without a metal catalyst, and that would make our research easier."

The basicity of the catalyst is clearly important in many base-catalyzed reactions, while the $K_{a}$ value is one of the criteria representing basicity. Thus, the group compared the $\mathrm{pK}_{a}$ values of raw material and several traditional anions. "To our



Figure 1 The $\mathrm{p} K_{a}$ relationship of the complex of $1 \mathrm{a}$ and $\mathrm{CO}_{2}$, $1 \mathrm{a}$ and anions surprise, diyne alcohol showed stronger basicity than imidazole," said Professor Wang. He continued: "Then, inspired by our previous findings that $\mathrm{CO}_{2}$ could facilitate hydrogen abstraction, we recalculated the $\mathrm{pK}_{a}$ value of $1 \mathrm{a}$ while $\mathrm{CO}_{2}$ was also taken into consideration. As shown in Figure 1 , the $\mathrm{p} K_{a}$ value of that complex decreased to between that of BenIm and Triz. To our delight, the prediction was consistent with experiments, where $\left[\mathrm{N}_{4444}\right]\left[\right.$ Triz] and $\left[\mathrm{N}_{4444}\right][$ BenIm] had better catalytic activities than other ILs."

However, the group was puzzled to find that the cations in the ILs also affected the reaction. Initially, the reaction mechanism was investigated by DFT calculations (Figure 2). Professor Wang explained: "By using NMR spectroscopic investigations (Figure 3) and DFT calculations, we found the basicity of ILs was different when they had different cations. Clearly, that is the reason that led to different catalytic activities."

Professor Wang remarked that this reaction can be expanded to other diyne alcohols, and the catalyst is reusable: "When $10 \mathrm{mmol}$ of $\mathbf{1 a}$ was used, a high yield of $\mathbf{2 a}$ was obtained after six hours," he added.

"Importantly, I believe this manuscript presents a strategy to predict the catalytic activities of catalysts before experiments. Notably, we also discovered the influence of cations by the combination of NMR spectra and quantum-chemical calculations," said Professor Wang.

He concluded: "We hope this method can be also used in other base-catalyzed reactions and CCU processes."

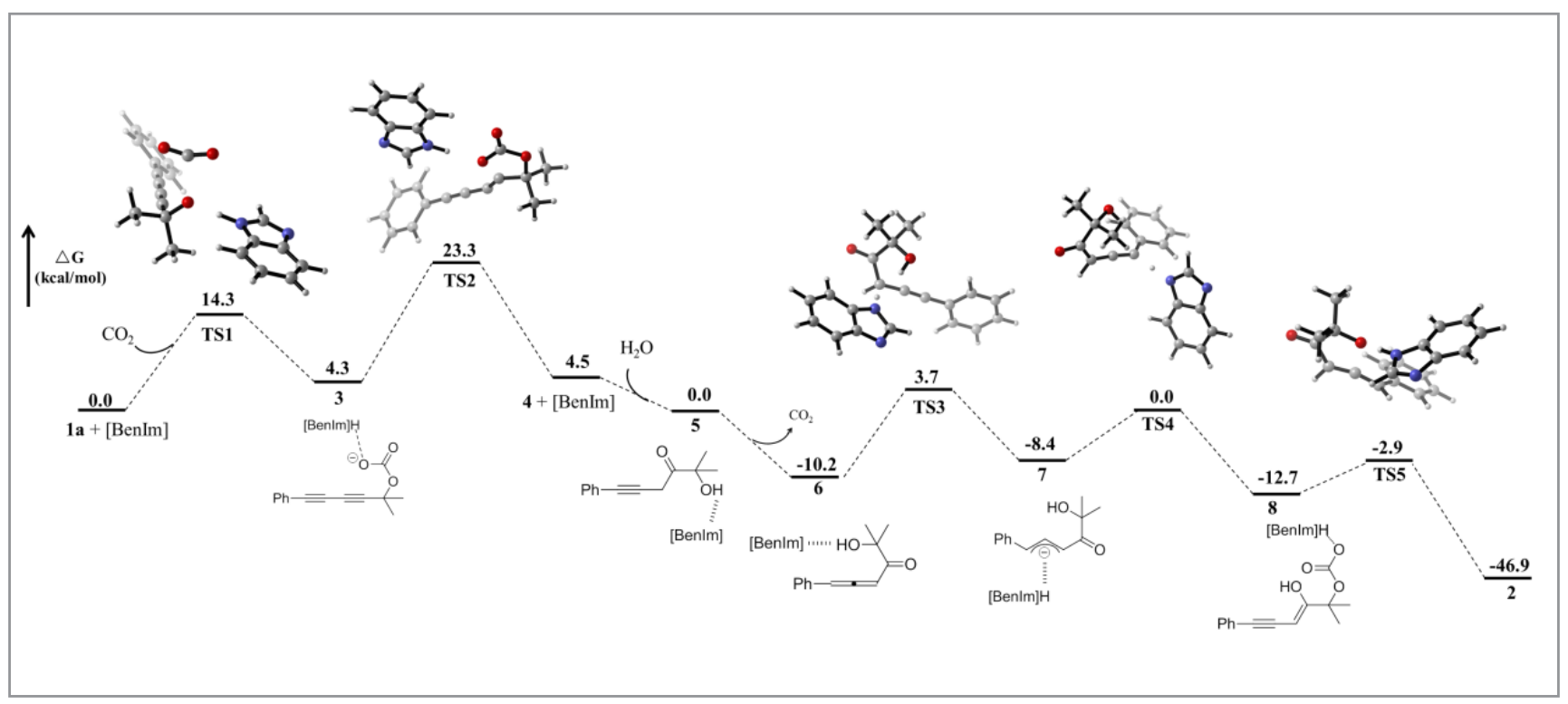

Figure 2 Computational studies of the reaction mechanism (reprinted with permission from J. Am. Chem. Soc. 2016, 138, 14198) 


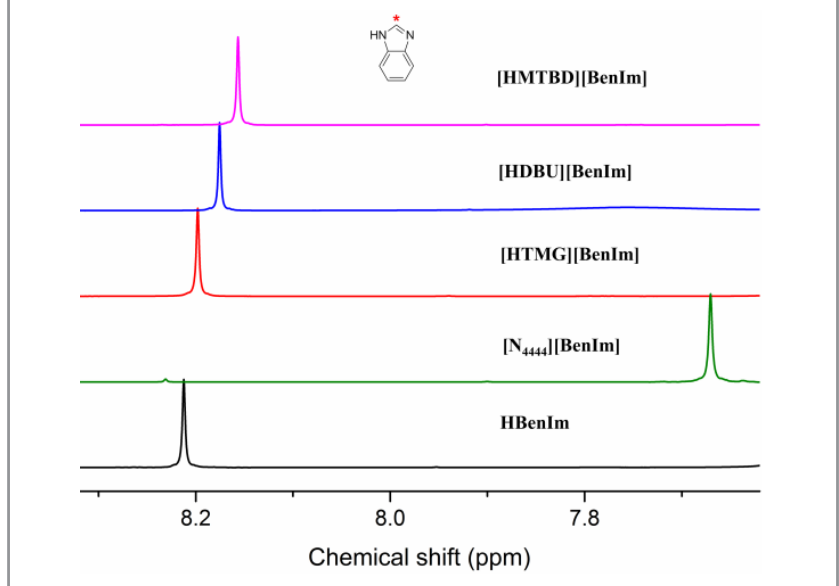

Figure $3^{1} \mathrm{H}$ NMR spectra of HBenlm, [ $\left.\mathrm{N}_{4444}\right][$ Benlm], [HTMG] [Benlm], [HDBU][Benlm] [HMTBD][Benlm]

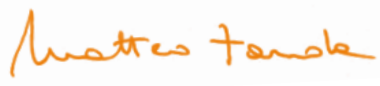

\section{REFERENCES}

(1) (a) C. Wang, X. Luo, H. Luo, D. Jiang, H. Li, S. Dai Angew. Chem. Int. Ed. 2011, 50, 4918; (b) K. Chen, W. Lin, X. Yu, X. Luo, F. Ding, X. He, H. Li, C. Wang AlChE J. 2015, 61, 2028.

(2) K. Chen, G. Shi, R. Dao, K. Mei, X. Zhou, H. Li, C. Wang Chem. Commun. 2016, 52, 7830.

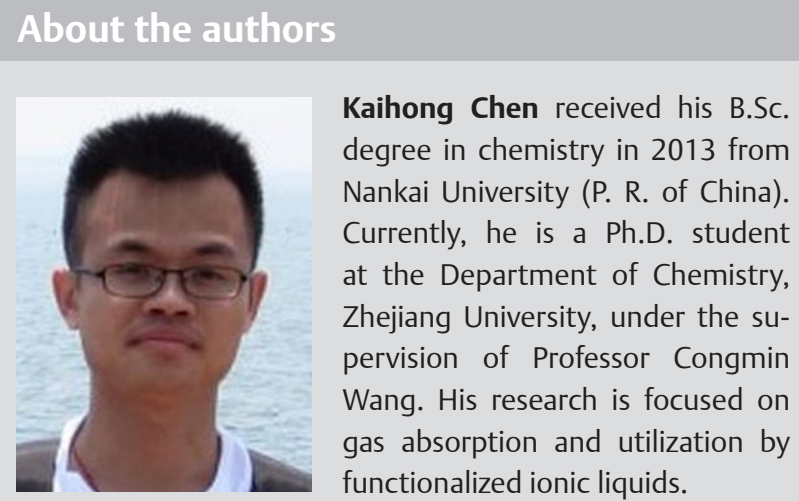

K. Chen

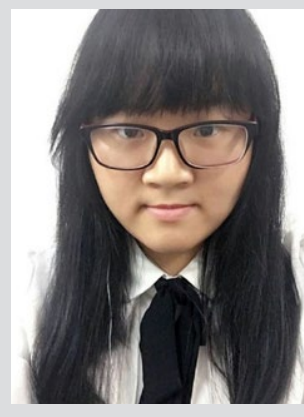

Guiling Shi graduated from the Department of Chemistry, Zhejiang University (P. R. of China) with a B.Sc. degree in 2015. She joined Professor Congmin Wang's group at Zhejiang University (P. R. of China) in autumn 2015 as a Ph.D. candidate. Her research interest is CCU process using functionalized ionic liquids.

\section{G. Shi}

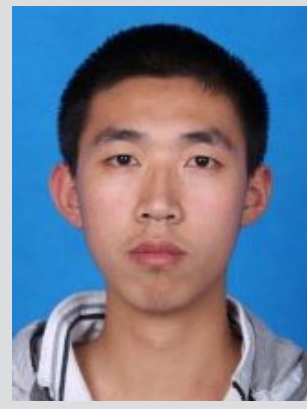

W. Zhang

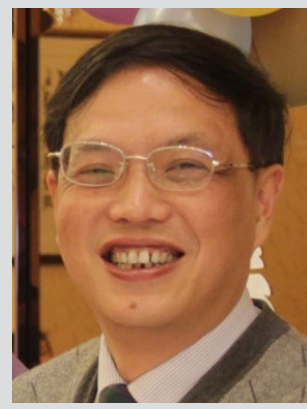

Weidong Zhang received his B.Sc. degree from Zhejiang University (P. R. of China) in 2016. He is currently a Ph.D. student in the Department of Chemistry, Zhejiang University, tutored by Professor Congmin Wang. His research interests concern green chemistry, with a focus on ionic liquids and their applications in the capture of acid gas and catalysis.

Haoran Li received his Ph.D. from Zhejiang University (P. R. of China) in 1995. After that, he joined Zhejiang University as a faculty member. In 1999, he became a Full Professor in the Department of Chemistry, Zhejiang University. He is currently Executive Dean of College of Science, Zhejiang University, and the Director of ZJU-NHU United

Prof. H. Li 
R\&D Center. Besides teaching, he conducts research on green chemistry, with a focus on ionic liquids and aerobic oxidation reactions, and holds several local and national awards.

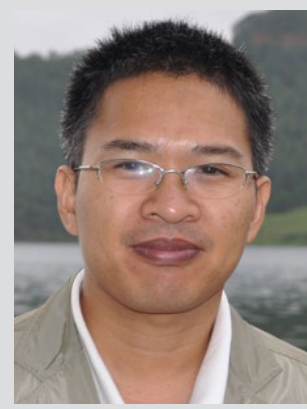

Prof. C. Wang
Congmin Wang received his B.Sc. degree in chemical engineering from Zhejiang University (P. R. of China) in 1996, and obtained his Ph.D. from the same university in 2002. In 2010, he became a Full Professor in the Department of Chemistry, Zhejiang University. He had worked as a visiting professor at the Oak Ridge National Laboratory (USA) in 2009 and 2011. His work is focused on the capture of acid gas and its utilization by functionalized ionic liquids. 


\title{
Total Chemical Synthesis of Proteins without HPLC Purification
}

\author{
Chem. Sci. 2016, 7, 6753-6759
}

The lab of Professor Oliver Seitz at the Humboldt University in Berlin (Germany) has a long-standing interest in the development of methods which facilitate the synthetic access to proteins for biological studies. Professor Seitz said: “Our first idea was to simplify the synthesis by means of surface-based chemistry. We envisioned the use of fully synthetic protein arrays. Both the synthesis and the biological evaluation of the targeted proteins would proceed in an array format (just as we know it from peptide arrays, but now with folded proteins). We were foreseeing large-scale studies on the influence of post-translational modification on protein-protein interactions." He continued: "While we were working towards achieving this goal (see Angew. Chem. Int. Ed. 2016, 55, 7252; J. Am. Chem. Soc. 2010, 132, 11110; Angew. Chem. Int. Ed. 2007, 46, 4577) we noticed that there is actually an increasing interest in soluble synthetic proteins to guide the development of protein-based drugs. Most recently we learned that chemical protein synthesis may even be an alternative to recombinant synthesis."

According to the authors, the method presented in the Chem. Sci. paper has at least six distinct advantages over currently used methods. Firstly, there is the potential for parallelization, whereas traditional methods of protein synthesis rely on HPLC for purification. Professor Seitz explained: "While it is no problem to perform peptide synthesis in parallel, parallelization of HPLC purification is a technological challenge. Let us imagine the parallel synthesis of 100 proteins. The HPLC purification of 100 proteins would call for a sizeable investment into technical infrastructure such as several multiple column HPLC devices, or purification is performed subsequently at the expense of time investment. The method developed by us overcomes the need for HPLC purification. Rather, the instrumental set-up for the entire purification process is based on low-priced filter-equipped plastic syringes and two commercially available "purification resins'."

Secondly, the presented method saves time. The authors explained that traditional protein synthesis methods require analysis and purification of both intermediary and final products (i.e. peptide fragments and ligation products) which is not only time-consuming but also requires human resources for the preparation of samples, analysis and subsequent lyophilization procedures. "Our approach bypasses the necessity for intermediary analysis. The purity of the intermediary products is not of concern because by-products will automa- tically be washed away at later stages," said Professor Seitz. Extended native chemical ligation and add-on removal of the ligation auxiliary are usually carried out in solution. However, the Seitz lab approach was different: "We performed both reactions on solid support. This enabled us to remove remaining peptide fragments, excess of reagents or exchange buffers within minutes by simple washing of the resin and consequently helped to further decrease the time required for the whole synthesis procedure," explained Professor Seitz.

The third advantage of this method is the reduction in the amount of waste products. "Considering the large amounts of organic solvents, the excess of protected amino acid building blocks and coupling activators wasted in the course of SPPS, chemical synthesis of peptides/proteins is anything but green. But the use of HPLC-based purification steps also contributes to an increased amount of toxic, in this case aqueous, waste," said Professor Seitz. He remarked: "We calculated that our approach produces approximately 60 times less waste than traditional synthesis with HPLC purification."

"Fourthly, this method has a potential for automation," said Professor Seitz, who explained that the synthesis of a fulllength protein usually requires the use of automated SPPS to obtain protein fragments and ligation techniques for the subsequent conjugation of the protein fragments. The synthesis of the protein fragments is performed by using peptide synthesizers in an automated and parallel manner. "The bottleneck of a fully automated and parallel chemical protein synthesis is the necessity for intermediate HPLC purifications, analysis and lyophilization steps," said Professor Seitz, adding: "Our method bypasses these obstacles. The crude peptide fragments obtained after SPPS can be used directly for the HPLCfree purification and peptide ligation process. The stoichiometry or purity of the crude fragments is not important, as the final product will be obtained in high purity anyway."

A fifth advantage is chemoselectivity vs HPLC purification. "At lengths above approximately 50 amino acids it is often difficult to separate full-length peptides from truncation products," said Professor Seitz. He noted that this problem becomes worse as the length of the target peptide/protein increases. "At large sizes the HPLC elution properties of peptides almost seem to converge. As a result, the single peak observed in HPLC trace may suggest purity but actually many by-products may be hiding underneath that peak," explained Professor Seitz. He continued: "In this case, catch-and-release-based 
A)

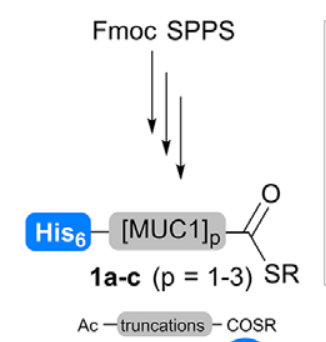

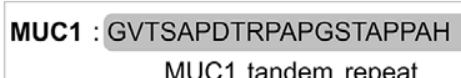

$\mathrm{Ni}=\mathrm{Ni}-\mathrm{NTA}$ agarose beads

$\mathrm{OHC}-\mathrm{=}=$ aldehyde agarose beads

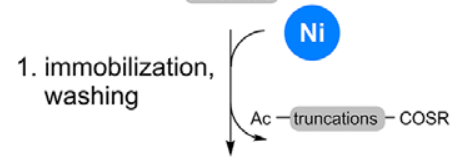

\section{Fmoc SPPS}

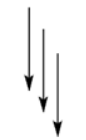

$\mathrm{Ni}-\mathrm{His}_{6}-[\mathrm{MUC1}]_{\mathrm{p}}-\mathrm{S}_{\mathrm{SR}}^{\mathrm{O}}$

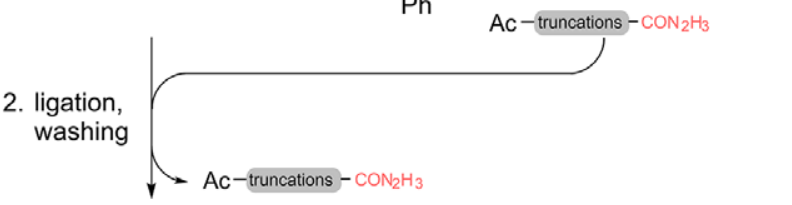

Ni $-\mathrm{His}_{6}-[\mathrm{MUC1}]_{\mathrm{p}}$

4. release

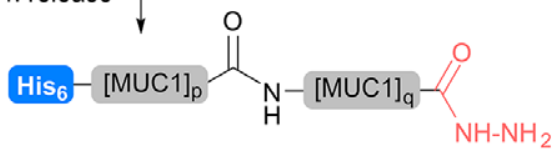

$\mathrm{His}_{6}-[\mathrm{MUC} 1]_{\mathrm{q}}-\mathrm{COOH}$

5. immobilization,



6. release

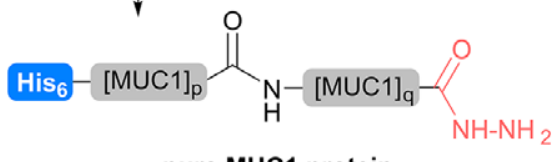

pure MUC1 protein

$$
3 a(p+q=2), \ldots 3 e(p+q=6)
$$

B)

\begin{tabular}{lcl} 
reaction & length & purity \\
\hline $\mathbf{1 a}+\mathbf{2 a} \rightarrow \mathbf{3 a}$ & $46 \mathrm{mer}$ & $96 \%$ \\
$\mathbf{1 a}+\mathbf{2 b} \rightarrow \mathbf{3 b}$ & $66 \mathrm{mer}$ & $98 \%$ \\
$\mathbf{1 a}+\mathbf{2 c} \rightarrow \mathbf{3 c}$ & $86 \mathrm{mer}$ & $90 \%$ \\
$\mathbf{1 b}+\mathbf{2 a} \rightarrow \mathbf{3 b}$ & $66 \mathrm{mer}$ & $91 \%$ \\
$\mathbf{1 b}+\mathbf{2 b} \rightarrow \mathbf{3 c}$ & $86 \mathrm{mer}$ & $96 \%$ \\
$\mathbf{1 b}+\mathbf{2 c} \rightarrow \mathbf{3 d}$ & $106 \mathrm{mer}$ & $93 \%$ \\
$\mathbf{1 c}+\mathbf{2 a} \rightarrow \mathbf{3 c}$ & $86 \mathrm{mer}$ & $92 \%$ \\
$\mathbf{1 c}+\mathbf{2 b} \rightarrow \mathbf{3 d}$ & $106 \mathrm{mer}$ & $93 \%$ \\
$\mathbf{1 c}+\mathbf{2 c} \rightarrow \mathbf{3 e}$ & $126 \mathrm{mer}$ & $90 \%$
\end{tabular}

C)
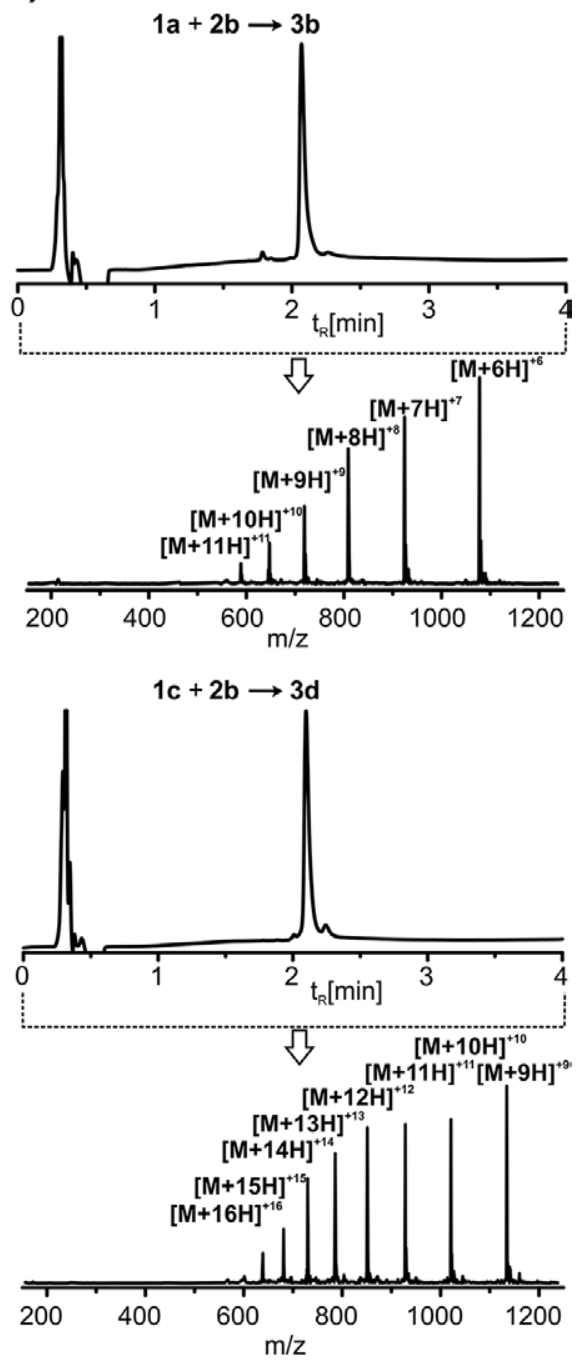

Figure 1 Chemical synthesis of MUC-1 proteins without HPLC purification: A) Non-chromatographic purification is achieved by immobilization reactions via the $\mathrm{N}$-terminal $\mathrm{His}_{6}$ tag (step 1) and the C-terminal hydrazide (step 5). Peptide thioesters $\mathbf{1 a}-\mathbf{c}$ and auxiliary-loaded peptides $\mathbf{2 a - c}$ are conjugated (step 3) upon extended native chemical ligation which relies on the 2-mercapto-2phenyl-ethyl auxiliary. The auxiliary is removed (step 4) under mild basic conditions. B) Purities of final MUC-1 proteins 3a-e and C)-D) UPLC-MS analyses of products $\mathbf{3 b}$ and $\mathbf{3 d}$. 
purification methods are superior, because only the full length protein will carry the purification tag, but not the truncations (which may have equal polarity). This is illustrated in Figure 2."

Solubility is yet another advantage of this method. Chemical protein synthesis is frequently faced with the problem of dealing with sparingly soluble peptide fragments. "While the crude material obtained after SPPS may still have sufficient solubility, the solubility problem becomes pressing during HPLC purification," said Professor Seitz. He continued: "The use of large amounts of denaturing agents such as guanidinium hydrochloride (added also in the native chemical ligation step) is not an option for HPLC as this will cause column overloading or even column damage. It is an advantage that our method tolerates the use of guanidinium hydrochloride."

State-of-the-art purification of proteins or peptides is done by HPLC-based methods and provides a purity of the final product greater than 95\% (typical high quality level offered from many peptide manufacturing companies). Professor Seitz remarked: "We were able to obtain similar purities (90-98\%) by using our HPLC-free purification approach, yet, as mentioned before, our method appears to be faster and cheaper. The quality of the final products should be sufficient for biological studies to guide screening efforts. Compared to proteins from recombinant sources, we have better batch-tobatch repeatability."
However, the method does have a few limitations. "Our case study involved the synthesis of mucin proteins. We selected a comparatively easy-to-form His-Gly bond," said Professor Seitz. He continued: "Still, the on-resin native chemical ligation required 24 hours. Even then, the ligation was not complete. How will the solid-supported native chemical ligation proceed when more challenging ligation sites are targeted? This will be problematic. Yet there is an easy solution to this problem. Rather than immobilizing the $\mathrm{N}$-terminal fragment prior to ligation, the ligation fragments may be mixed in solution phase prior to immobilization. Native chemical ligation proceeds much faster in solution. After the solution-phase ligation, the affinity capture resin will be added to selectively extract products that contain the fulllength N-terminal fragment."

Professor Seitz concluded: "We foresee two types of application. In one scenario, the method will be used for the parallel synthesis of proteins for subsequent screening in biological and biomedical research. Here, the full potential of chemistry can be unraveled in the synthesis of protein modifications not accessible by biological methods. In the second scenario, the method will be used to facilitate production of proteins when recombinant methods may either not provide access to the targeted modification or produce undesired by-products with batch-to-batch variations."



A)



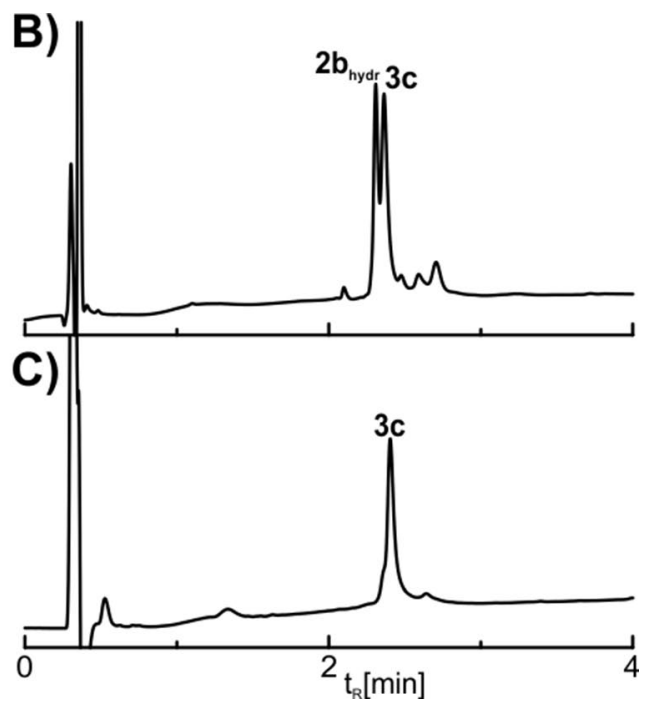

Figure 2 Reactivity-based purification as an alternative for difficult chromatographic purification: A) Chemoselective catch-andrelease from aldehyde-agarose enables the separation of MUC1- protein $3 \mathrm{c}$ from hydrolyzed peptide thioester $\mathbf{2}_{\text {bhydr. }}$ B)-C) UPLC analysis of the mixture of $3 c$ and $\mathbf{2}_{\text {bhydr }}$ and the purified MUC-1 protein $3 c$. 


\section{About the authors}

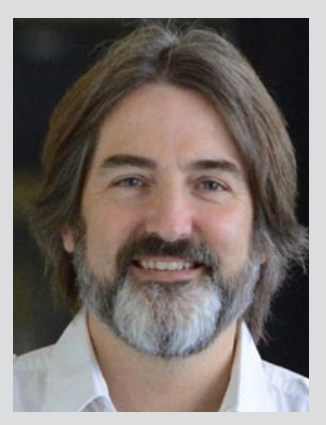

Prof. O. Seitz
Oliver Seitz was born in Frankfurt/ Main (Germany) and studied chemistry at the Johannes-Gutenberg University Mainz (Germany). There he obtained his Ph.D. in organic chemistry with Horst Kunz. After postdoctoral research with Chi-Huey Wong at the Scripps Research Institute in La Jolla (USA) he moved to the Technical University Karlsruhe (Germany). He became group leader in the Department of Chemical Biology at the Max-Planck Institute for Molecular Physiology and obtained the venia legendi in organic chemistry from the Technical University Dortmund (Germany). In 2003, he was appointed Full Professor at the Humboldt University of Berlin (Germany). He is broadly interested in fashioning nucleic acid and protein molecules and their conjugates to enabling tools for the life sciences.

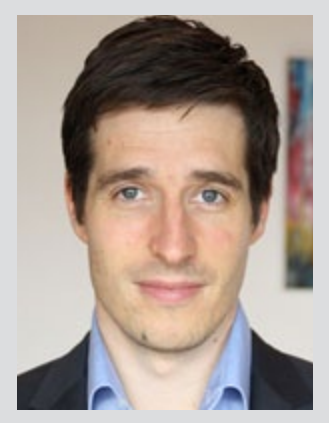

S. Loibl
Simon Loibl received his diploma (2011) in chemistry at the Humboldt University of Berlin (Germany) for his work with Oliver Seitz on LNAenhanced FIT hybridization probes for DNA/RNA detection. The diploma thesis included an internship at the University of Southern Denmark where he worked in the group of Jesper Wengel. Simon is currently completing his Ph.D. work in the Seitz group. His thesis will describe the development of highly efficient $\mathrm{N}^{\alpha}$-auxiliaries for extended native chemical ligation.

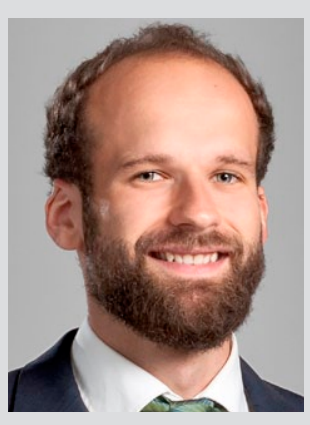

Dr. R. Zitterbart
Robert Zitterbart studied chemistry at the Humboldt University of Berlin (Germany). For his diploma thesis, he worked in 2010 with K. P. C. Vollhardt at UC Berkeley (USA). In 2011, he started his Ph.D. work under the mentorship of Oliver Seitz on the chemical synthesis of protein domain arrays. After completion of his Ph.D. in 2016, he started a spin-off with two friends, which is based on a patent-pending technology for the HPLC-free purification of peptides. The start-up 'EnviroPep' was awarded with the first prize of Berlin's business plan competition (BPW) in 2015 and received funding in 2016 from the EXIST program financed by the Bundesministerium für Wirtschaft und Energie and the European Social Fund.

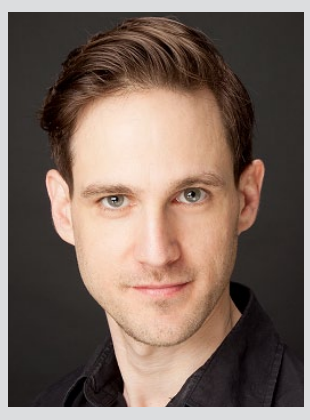

Dr. Z. Harpaz University of the Negev (Israel) and completed B.Sc. and M.Sc. degrees in chemistry. In 2010, he joined the Seitz group at the Humboldt University in Berlin (Germany), where he was awarded his $\mathrm{PhD}$ in chemistry with specialization in bioorganic chemistry. He now works as a chemistry lecturer at Berlin Medical College (Germany).
Ziv Harpaz studied at Ben-Gurion 


\title{
Deoxyfluorination of Alcohols with 3,3-Difluoro-1,2-diaryl- cyclopropenes
}

\author{
Nat. Commun. 2016, 7, 13320
}

The unique characteristics of fluorine-containing substituents and their effects on molecular properties have led to numerous applications of organofluorine compounds in medicinal chemistry, chemical biology and drug discovery. Alkyl fluorides constitute a valuable class of organofluorine compounds for $\mathrm{p} K_{a}$ modulation, lipophilicity tuning, and selective blocking of oxidative metabolism. ${ }^{1}$ Consequently, a myriad of fluorination methods have been developed for their synthesis. Among them, the deoxyfluorination of alcohols via in situ activation is a leading approach due to the ready availability of both natural and synthetic alcohols. ${ }^{2}$

Known deoxyfluorination reactions mainly rely on 'S-F' reagents (such as DAST, Deoxo-Fluor, XtalFluor, Fluolead, and PyFluor) and 'N-C-F' reagents s such as Ishikawa reagent, $N$-[difluoro( $m$-tolyl)methyl]- $N$-ethylethanamine, PhenoFluor, and recently developed AlkylFluor\}, which facilitate the replacement of an $\mathrm{OH}$ group with fluorine by means of heteroatom-promoted activation of alcohols followed by the nucleo- philic attack of self-released or external fluoride ion. ${ }^{2}$ While these reagents possess features such as high reactivity, good chemoselectivity, enhanced shelf stability, ready availability or low cost, their selective reaction with multiple alcohols is usually paid little attention, except in the case of PhenoFluor, with apparently sterically controlled selectivity. Moreover, there is still a lack of a deoxyfluorination method that is capable of fluorinating multiple alcohols selectively at the relatively electron-rich position rather than the less sterically hindered position.

To tackle the existing chemoselectivity problem, the group of Professor Jinbo Hu from the Shanghai Institute of Organic Chemistry, Chinese Academy of Sciences (P. R. of China) developed a novel strategy for the deoxyfluorination of alcohols based on cyclopropenium cation activation by use of 3,3-difluoro-1,2-diarylcyclopropenes (CpFluors) as easily accessible and reactivity-tunable reagents (Scheme 1). The synthetic potential of this strategy is demonstrated by the fluorination of

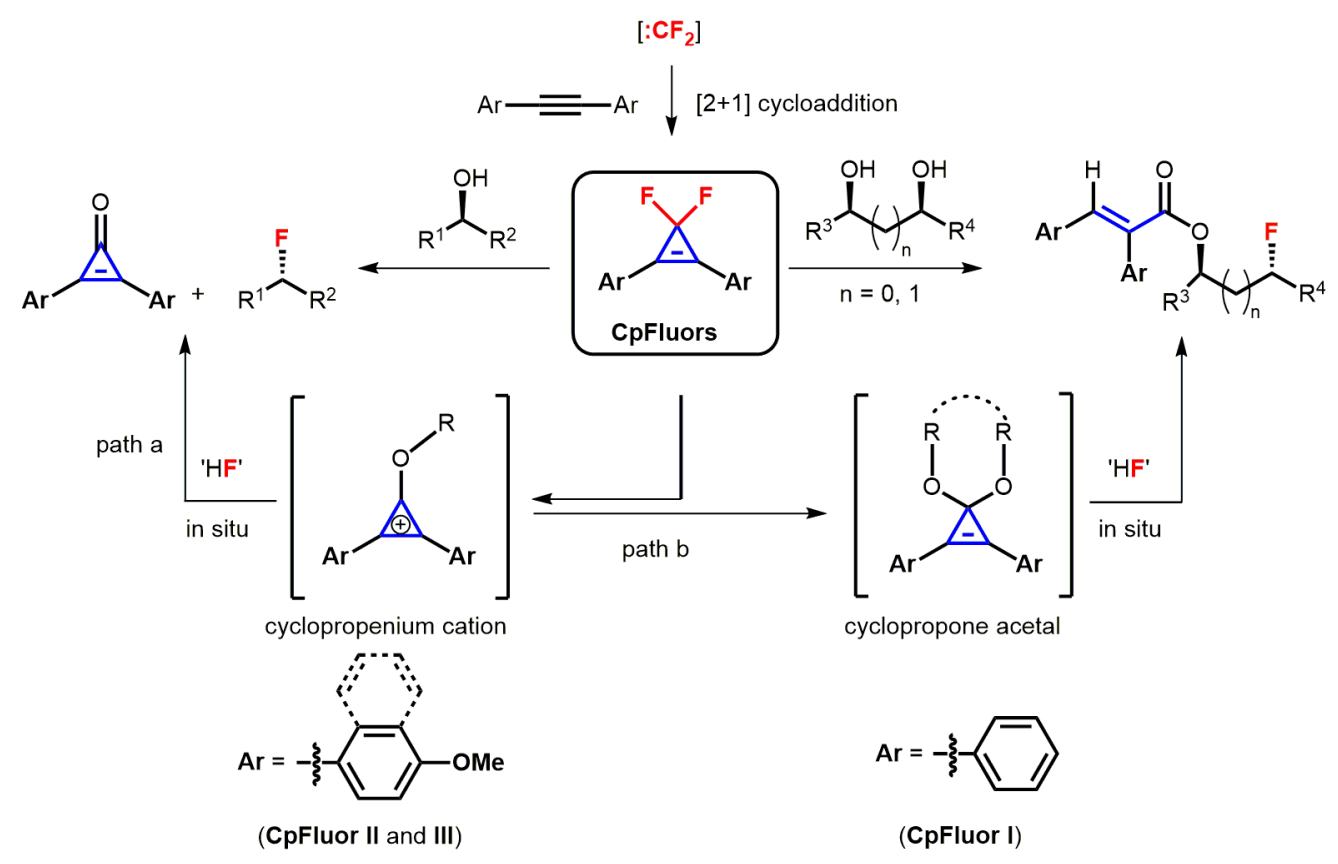

Scheme 1 Pathways for deoxyfluorination of alcohols with CpFluors 
monoalcohols, fluorinative acylation of 1,2- and 1,3-diols, and selective fluorination of electron-rich alcohols.

Professor Hu explained: "Cyclopropenium cations have considerable thermodynamic stability owing to the Hückel aromaticity, and the stability and reactivity of this class of molecules can be tuned by changing the electronic property of the substituents. As unique molecules with the binary properties of aromatic stability and ionic charge, they have been used for deoxyfunctionalization and in organic catalysis. However, their use for deoxyfluorination is a great challenge due to the low nucleophilicity of the fluoride ion and the corrosive nature of HF towards glass." Professor Hu continued: "Actually, we had started the project more than six years ago, when Professor Tristan H. Lambert and his co-worker from Columbia University (USA) just published a paper on the chlorination of alcohols with gem-dichlorocyclopropenes. ${ }^{3}$ It happened that at the time we were working on the synthesis of gem-difluorocyclopropenes with difluorocarbene. ${ }^{4}$ Inspired by our interest on difluorocarbene chemistry and Professor Lambert's work on cyclopropenium cation activation, we decided to use the readily available difluorocarbene reagents as the source of fluoride for deoxyfluorination by virtue of the thermally stable gem-difluorocyclopropenes, hoping that we could develop a practical method for the fluorination of alcohols."

Professor Hu revealed that initially numerous experiments evaluating the deoxyfluorination ability of 3,3-difluoro-1,2diphenylcyclopropene (CpFluor I) were performed in glassware by Dr. Fei Wang, a senior graduate student at that time. "Interestingly, Dr. Wang found that this fluorination had only a limited scope of substrates including carboxylic acids and benzylic alcohols, ${ }^{5}$ which is different from Lambert's chlori- nation chemistry," recalled Professor Hu, adding: "Fortunately, we did not give up this project. After the graduation of Dr. Wang, Dr. Lingchun Li joined our group as a graduate student and he took up Dr. Wang's project. Dr. Li is scrupulous, and he found that the fluorination of non-activated monoalcohols with CpFluor I could be achieved by performing the reaction in non-glass ware to avoid corrosion by HF, although the highest yield was only moderate. With the help of Dr. Chuanfa $\mathrm{Ni}$, an associate professor, also my first graduate student, Dr. Li eventually established that there was one more difference between the fluorination and chlorination after months of experimental investigations." Professor Hu explained: "Because the fluoride ion is less nucleophilic than the chloride ion, the charged reactive intermediate, an alkoxycyclopropenium cation, prefers to form a neutral intermediate, a cyclopropenone acetal, rather than undergoing nucleophilic substitution by fluoride ion. The cyclopropenone acetal is also reactive but contributes less to the desired fluorination of monoalcohols. As a matter of fact," continued Professor Hu: "by taking advantage of this feature, we easily achieved the fluorination of 1,2and 1,3-diols with CpFluor I (Scheme 2), in which the cyclic acetal intermediates, 1,3-dioxolanes and 1,3-dioxanes, readily formed regardless of the electronic nature of 3,3-difluoro-1,2diarylcyclopropenes, thus always furnishing the fluorinative acylation products in high yields through thermally induced ring opening of the electron-rich cyclopropenes followed by fluorination."

Eventually, the group was delighted to find that the pathway for fluorination of monoalcohols could be switched by changing the electronic properties of CpFluors (Scheme 3). "Electron-rich aryl substituents are beneficial for the formation and stabilization of the alkoxycyclopropenium

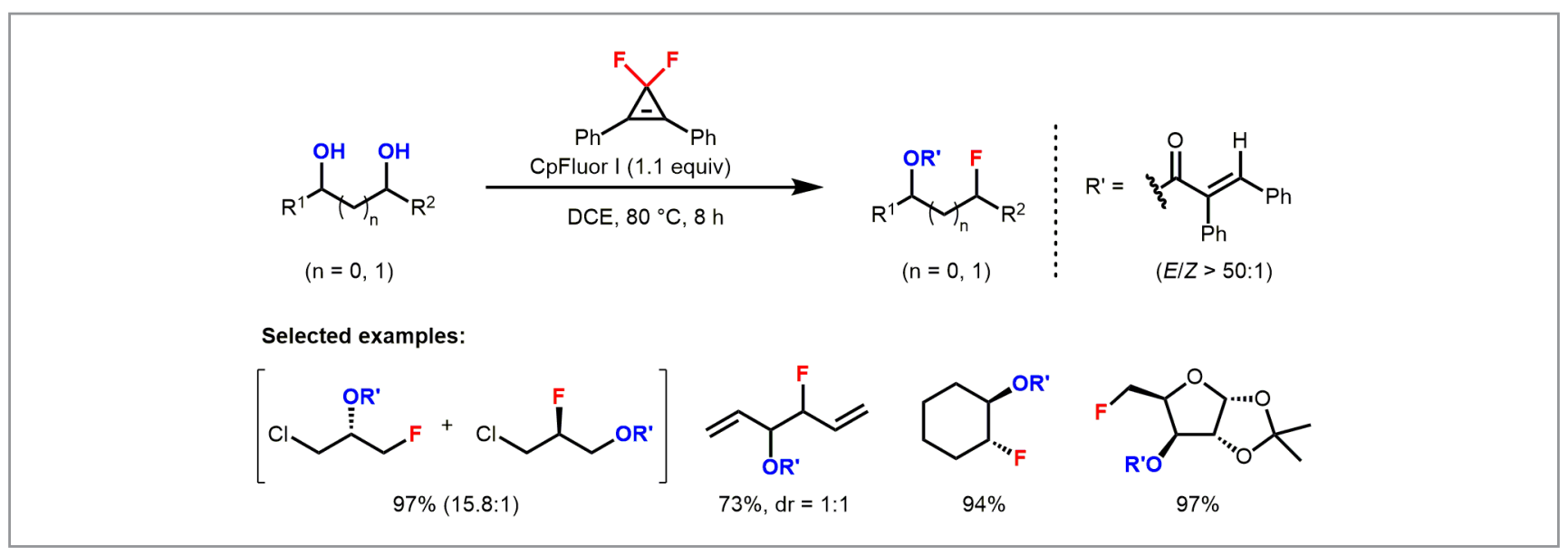

Scheme 2 Deoxyfluorination of 1,2- and 1,3-diols with CpFluor I 
cations, thus facilitating the fluorination of monoalcohols with high efficiency. Employing 3,3-difluoro-1,2-bis(4'methoxynaphthalen-1'-yl)cyclopropene (CpFluor II) or 3,3-difluoro-1,2-bis(4'-methoxyphenyl)cyclopropene (CpFluor III) as the reagent, a series of primary and secondary monoalcohols smoothly underwent the deoxyfluorination to give alkyl fluorides in moderate to excellent yields," explained Professor Hu. "Chiral secondary alcohols were normally deoxyfluorinated with inversion of configuration."

The invention of CpFluors as efficient deoxyfluorination reagents provided the group an opportunity to exploit the aforementioned challenging task, that is, selective fluorination of electron-rich alcohols (Scheme 4). Professor Hu explained: "The observation that the fluorination pathway of a given alcohol was sensitive to the electronic nature of CpFluors indicates that the chemical outcome of this fluorination method should also be sensitive to the electronic nature of alcohols, because both the alkoxy substituent and the aryl substituents can influence the stabilization of the cyclopropenium cation intermediate." At first, Dr. Li and Dr. Ni conducted the competitive deoxyfluorination of two monoalcohols by the use of CpFluor III as the reagent and found that electron-rich alcohols did react faster than the relatively electron-poor ones. Having developed a proof-of-concept, the authors applied it in the transformation of diols with hydroxyl groups separated by several carbon centers. "Compared with other reagents such as DAST, PhenoFluor and PyFluor, CpFluor reagents are the most sensitive towards the electronic nature of the alcohols, which represents a breakthrough in deoxyfluorination of alcohols," said Professor Hu.

"In conclusion, an alcohol fluorination protocol using CpFluors as a novel class of deoxyfluorination reagents has been developed after a long-standing pursuit," said Professor Hu. "The finding that the electronic properties of the aryl substituents on the scaffold of CpFluors can dramatically influence the transformation of alcohols is instructive, which shows the way for achieving selective fluorination of electronrich alcohols." He concluded: "This research also sheds light on the divergent reactivity of cyclopropenium cations in the transformation of alcohols. We hope that this concept will find application in other selective deoxyfunctionalizations of alcohols."

<smiles>[R]C([R])([R])O[Na]</smiles>

Selected examples:<smiles>FCCCc1ccc(-c2ccccc2)cc1</smiles>

$86 \%($ CpFluor II)<smiles>CS(=O)(=O)c1ccc(CF)cc1</smiles>

$97 \%$ (CpFluor II)<smiles>FCCCc1cccnc1</smiles>

54\% (CpFluor III, with Py-10HF)

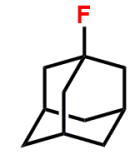

83\% (CpFluor II)

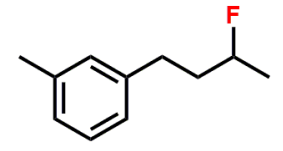

81\% (CpFluor II) 74\% (CpFluor III)<smiles>C[C@H]1C[C@H](F)c2ccsc2S1(=O)=O</smiles>

$99 \%, d r=6.9: 1$ (CpFluor II)<smiles>C[C@H](F)CCCc1cccc2ccccc12</smiles>

$80 \%, 96.6 \%$ es (CpFluor II)<smiles>O=Cc1ccc(C(=O)N2CC[C@H](F)C2)cc1</smiles>

$68 \%, 96.1 \%$ es (CpFluor II)<smiles>O=S(=O)(c1ccc(Br)cc1)N1CC[C@H](F)C1</smiles>

$69 \%, 97.2 \%$ es (CpFluor III)

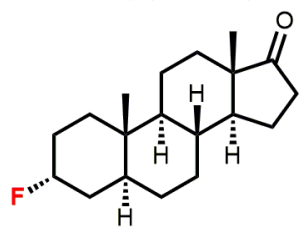

72\% (CpFluor II)

Scheme 3 Deoxyfluorination of monoalcohols with CpFluor II and III; es refers to enantiospecificity: es = (ee of starting material)/ (ee of product) $\times 100 \%$. 


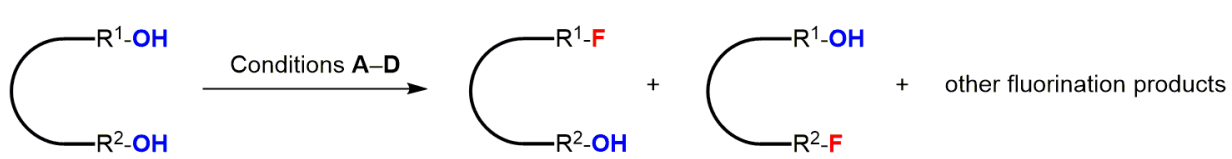

A: CpFluor III ( 1.1 equiv), DCE $(0.13 \mathrm{M}), 80^{\circ} \mathrm{C}, 8 \mathrm{~h}$

B: DAST ( 1.1 equiv), $\mathrm{CH}_{2} \mathrm{Cl}_{2}(0.1 \mathrm{M}),-78^{\circ} \mathrm{C}$ to r.t., $12 \mathrm{~h}$

C: PhenoFluor (1.2 equiv), KF (2.0 equiv), DIPEA (2.0 equiv), PhMe $(0.04 \mathrm{M}), 80^{\circ} \mathrm{C}, 12 \mathrm{~h}$

D: PyFluor (1.1 equiv), MTBD (2.0 equiv), PhMe (0.5 M), r.t., $48 \mathrm{~h}$

Selected examples:

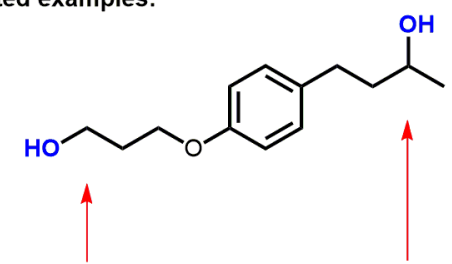
A: $13 \%$
$65 \%(41 \%)$
B: $29 \%$
$35 \%$
C: $76 \%$
$44 \%$
D: $56 \%(46 \%)$

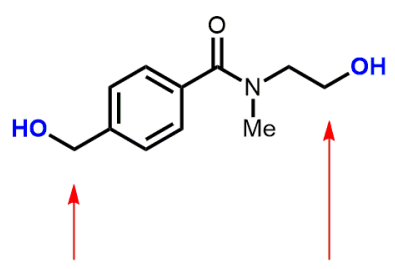
A: n.d.
$87 \%(74 \%)$
B: $42 \%$
$8 \%$
C: $48 \%$
$24 \%$
D: $2 \%$
n.d.

Scheme 4 Selective deoxyfluorination of electron-rich alcohols with CpFluor III (yields are total fluorination yields at the given position determined by ${ }^{19} \mathrm{~F}$ NMR spectroscopy, yields in parentheses refer to isolated yields of monofluorination products with retention of the other hydroxyl group)

\section{REFERENCES}

(1) Q. A. Huchet, B. Kuhn, B. Wagner, N. A. Kratochwil, H. Fischer, M. Kansy, D. Zimmerli, E. M. Carreira, K. Müller J. Med. Chem. 2015, 58, 9041.

(2) For a review: (a) P. A. Champagne, J. Desroches, J.-D. Hamel, M. Vandamme, J.-F. Paquin Chem. Rev. 2015, 115, 9073; For recent examples: (b) M. K. Nielsen, C. R. Ugaz,

W. Li, A. G. Doyle J. Am. Chem. Soc. 2015, 137, 9571;

(c) N. W. Goldberg, X. Shen, J. Li, T. Ritter Org. Lett. 2016, 18,

6102.

(3) B. D. Kelly, T. H. Lambert J. Am. Chem. Soc. 2009, 131, 13930.

(4) (a) F. Wang, W. Zhang, J. Zhu, H. Li, K.-W. Huang, J. Hu Chem. Commun. 2011, 47, 2411; For a review: (b) C. Ni, J. Hu Synthesis 2014, 46, 842.

(5) (a) F. Wang, Ph.D. dissertation, Shanghai Institute of Organic Chemistry, CAS, 2011; (b) J. Hu, F. Wang, M. Hu, X. Shen, T. Luo Chinese Patent CN 102285849 A, 2011. 


\section{About the authors}

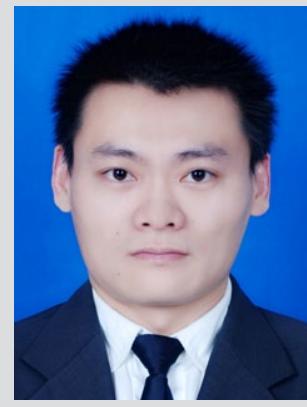

Dr. L. Li
Lingchun Li was born in Jiangsu (P. R. of China) in 1988. He obtained his BSc degree from Tongji University (P. R. of China) in 2010 and his Ph.D. in organic chemistry from Shanghai Institute of Organic Chemistry (SIOC), Chinese Academy of Sciences in 2015 under the supervision of Professor Jinbo Hu. Then he joined a SIOC and Merck Sharp \& Dohme (MSD) joint postdoctoral program under the supervision of Prof. Jinbo Hu (SIOC) and Dr. Yongxin Han (MSD) (2015-2016). His research involved fluoroalkylation and fluorination based on difluorocarbene chemistry. Currently he is studying ATRP with Professor Krzysztof Matyjaszewski at Carnegie Mellon University as a visiting scholar with an SIOC fellowship.

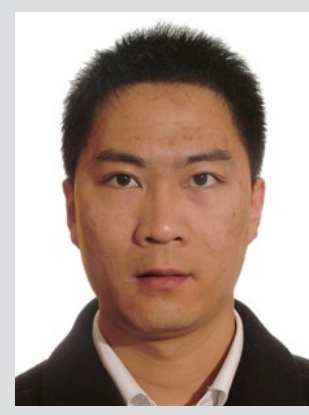

Dr. C. Ni
Chuanfa Ni obtained his BSc degree in chemistry from Shandong Normal University in 2003. After graduate work (2003-2009) at the Shanghai Institute of Organic Chemistry (SIOC) under the supervision of Professor jinbo $\mathrm{Hu}$ and postdoctoral work (2009-2012) at the University of Southern California under the supervision of Professor G. K. Surya Prakash, he has worked as an associate professor at Professor Jinbo Hu's group since 2012.

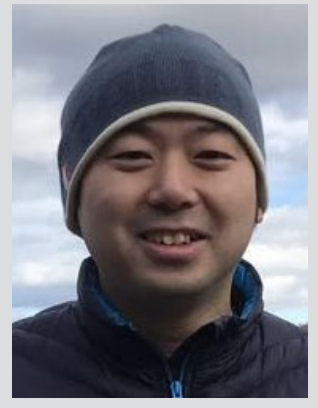

Fei Wang was born in Zhengjiang, China, in 1983. He received his B.S degree in chemistry from Ocean University of China in 2006, then he began his graduate studies at Shanghai Institute of Organic Chemistry (SIOC) with a focus on the development of novel difluorocarbene and fluorinating reagents under the supervision of Professor jinbo $\mathrm{Hu}$, and he was Dr. F. Wang awarded his Ph.D. from SIOC in 2011. He carried out postdoctoral work from 2011 to 2015 at the University of Florida. He is currently a Sr. Organic Chemist at Walter Reed Army Institute of Research.

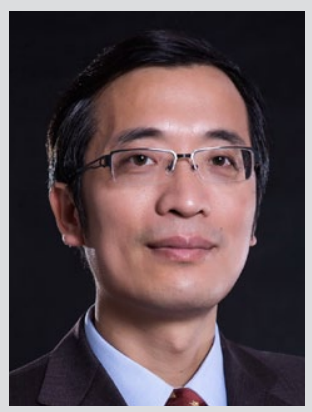

Jinbo Hu was born in Zhejiang, China, in 1973. After he completed his BS (Hangzhou University) and MS (Chinese Academy of Sciences) degrees, he carried out his PhD work from 1997 to 2002 at the University of Southern California with Professors G. K. Surya Prakash and G. A. Olah. After his postdoctoral work at USC, he accepted a Research Professorship Prof. J. Hu at the Shanghai Institute of Organic Chemistry, Chinese Academy of Sciences (SIOC, CAS) in early 2005, where he is currently the Head of the CAS Key Laboratory of Organofluorine Chemistry. $\mathrm{He}$ is the recipient of the RSC Fluorine Prize 2009 and the Novartis Chemistry Lectureship 2015-2016. His current research interests include selective fluorination, defluorination, fluoroalkylation methods, and fluorinated materials. 


\section{Coming soon}

- SYNTHESIS Highlight

A General and Robust Method for the Preparation of (E)- and (Z)-Stereodefined Fully Substituted Enol Tosylates: Promising Cross-Coupling Partners

- Literature Coverage

Borane-Catalyzed Ring-Opening and -Closing Cascades of Furans Leading to Silicon-Functionalized Synthetic Intermediates

\section{- Literature Coverage}

\section{Enantioselective Photochemistry through Lewis Acid Catalyzed Triplet Energy Transfer}

\section{Further highlights}

Synthesis Review: Recent Advances in the Arylation and Alkenylation of $\mathrm{N}-\mathrm{O}$ Bonds

(by G.-F. Su, D.-L. Mo and co-workers)

\section{Synlett Account: What's Golden: Recent Advances in} Organic Transformations Using Photoredox Gold Catalysis (by L. Barriault and co-workers)

\section{Synfacts Synfact of the Month in category "Metal-Catal-} yzed Asymmetric Synthesis and Stereoselective Reactions": Enantioselective Coupling of Diazoalkanes with Terminal Alkynes
Editor

Matteo Zanda, NRP Chair in Medical Technologies, Institute of Medical Sciences, University of Aberdeen, Foresterhill, Aberdeen, AB25 2ZD, UK and

C.N.R. - Istituto di Chimica del Riconoscimento Molecolare Via Mancinelli, 7, 20131 Milano, Italy

Editorial Assistant: Alison M. Sage

synform@outlook.com; fax: +3902 23993080

\section{Editorial Office}

Managing Editor: Susanne Haak,

susanne.haak@thieme.de, phone: +497118931786

- Scientific Editor: Michael Binanzer,

michael.binanzer@thieme.de, phone: +49 7118931768

- Scientific Editor: Stefanie Baumann,

stefanie.baumann@thieme.de, phone: +49 7118931776

Scientific Editor: Selena Boothroyd,

selena.boothroyd@thieme.de

- Assistant Scientific Editor: Kathrin Ulbrich,

kathrin.ulbrich@thieme.de, phone: +49711 8931785

- Senior Production Editor: Thomas Loop,

thomas.loop@thieme.de, phone: +49 7118931778

- Production Editor: Thorsten Schön,

thorsten.schoen@thieme.de, phone: +49 7118931781

Editorial Assistant: Sabine Heller,

sabine.heller@thieme.de, phone: +49 7118931744

- Senior Marketing Manager: Julia Stötzner,

julia.stoetzner@thieme.de, phone: +497118931771

Postal Address: Chemistry Journals, Editorial Office, Georg Thieme Verlag KG,

Rüdigerstraße 14, 70469 Stuttgart, Germany,

- Homepage: www.thieme-chemistry.com

Publication Information

Synform will be published 12 times in 2017 by Georg Thieme Verlag KG, Rüdigerstraße 14 70469 Stuttgart, Germany, and is an additional online service for Synthesis, Synlett and

Synfacts.

Publication Policy

Product names which are in fact registered trademarks may not have been specifically designated as such in every case. Thus, in those cases where a product has been referre to by its registered trademark it cannot be concluded that the name used is public

domain. The same applies as regards patents or registered designs.

Ordering Information for Print Subscriptions to Synthesis, Synlett and Synfacts The Americas: Thieme Publishers New York, Thieme Medical Publishers, Inc., 333 Seventh Avenue, New York, NY 10001, USA.

Via e-mail: customerservice@thieme.com

Via website: www.thieme-chemistry.com

Phone: +1 212760 0888; Fax: +1 2129471112

Order toll-free within the USA: +1 8007823488

Europe, Africa, Asia, and Australia: Thieme Publishers Stuttgart, Georg Thieme Verlag KC, Rüdigerstraße 14, 70469 Stuttgart, Germany.

Via e-mail: customerservice@thieme.de

Via website: www.thieme-chemistry.com

Phone: +49 7118931 421; Fax: +497118931410

Current list prices are available through www.thieme-chemistry.com.

Online Access

The online versions of Synform as well Synthesis, Synlett, Synfacts and SynOpen are available through www.thiemeconnect.com/products/ejournals/journals) where it is also possible to register for a free trial account. For information on multi-site licenses and pricing for corporate customers as well as backfiles, please contact our regional offices: The Americas: esales@thieme.com, phone: +1 2125844695

Europe, Africa, Asia, and Australia: eproducts@thieme.de, phone: +49 7118931407 India: eproducts@thieme.in, phone +91 1204556600

Japan: brhosoya@poplar.ocn.ne.jp, phone +8133358 0692

Manuscript Submission to Synthesis, Synlett, and SynOpen Manuscript submissions will be processed exclusively online via

http://mc.manuscriptcentral.com/synthesis, http://mc.manuscriptcentral.com/synlett and http://mc.manuscriptcentral.com/synopen, respectively. Please consult the Instructions for Authors before compiling a new manuscript. The current version and the Word template for manuscript preparation are available for download at www.thieme-chemistry.com.

Copyright

This publication, including all individual contributions and illustrations published therein, is legally protected by copyright for the duration of the copyright period. Any use, exploitation or commercialization outside the narrow limits set by copyright legislation, without the publisher's consent, is illegal and liable to criminal prosecution. This applies to translating, copying and reproduction in printed or electronic media forms (databases, online network systems, Internet, broadcasting, telecasting, CD-ROM, hard disk storage, microcopy edition, photomechanical and other reproduction methods) as well as making the material accessible to users of such media (e.g., as online or offline backfiles).

Copyright Permission for Users in the USA

Authorization to photocopy items for internal or personal use, or the internal or personal use of specific clients, is granted by Georg Thieme Verlag KG Stuttgart - New York for libraries and other users registered with the Copyright Clearance Center (CCC) Transactional Reporting Service, provided that the base fee of US $\$ 25.00$ per copy of each article is paid directly to CCC, 22 Rosewood Drive, Danvers, MA 01923, USA, 0341-0501/02.
SYNFORM issue 2017/03 is available from February 15, 2017

at www.thieme-connect.com/ejournals 